Harald C. Traue, Russell M. Deighton \& Petra Ritschi

\title{
Emotional Inhibition and Disease
}

International Institute for

Bioenergetic Analysis ted.

Analysis

2005 (15)
Bioenergetic Analysis

15. Volume, No. 1, 2005, Page 55-88

Psychosozial-Verlag

DOI: 10.30820/0743-4804-2005-15-55 
Bibliographic information of Die Deutsche Nationalbibliothek (The German Library) The Deutsche Nationalbibliothek lists this publication in the Deutsche Nationalbibliografie; detailed bibliographic data are available at http://dnb.d-nb.de.

2005 Psychosozial-Verlag GmbH \& Co. KG, Gießen, Germany

info@psychosozial-verlag.de

www.psychosozial-verlag.de

\section{(C) $(1) \Theta \Theta$}

This work is licensed under the Creative Commons Attribution-NonCommercialNoDerivatives 4.0 International License (CC BY-NC-ND 4.0). This license allows private use and unmodified distribution, but prohibits editing and commercial use (further information can be found at: https://creativecommons.org/licenses/by-nc-nd/4.0/). The terms of the Creative Commons licence only apply to the original material. The reuse of material from other sources (marked with a reference) such as charts, illustrations, photos and text extracts may require further permission for use from the respective copyrights holder.

Cover layout: Christof Röhl

Editorial staff: Kristine Klein

Layout: Katharina Appel

https://doi.org/10.30820/0743-4804-2005-15

ISBN (PDF-E-Book) 9978-3-8379-6805-7

ISBN (Print) 978-3-89806-395-1

ISSN (Online) 2747-8882 · ISSN (Print) 0743-4804 


\title{
Emotional Inhibition and Disease
}

\author{
Harald C. Trane, Russell M. Deighton and Petra Ritschi
}

The assertion that suppressed feelings are dangerous for health is a crucial component of non-professional disease theories. »Due to the fact that I swallow everything, my stomach aches all the time « is for example, such a self-diagnosis. These assumptions have their source in a long scientific tradition. William James (1890), the philosopher and founder of empirical psychology, was probably the first of the academic psychologists to take the view that suppressed feelings can cause physical diseases, worry and inner restlessness. But William James, who also wrote about religious issues, surely knew psalm 32 which says: »When I kept silence, my bones waxed old through my roaring all the day long «. He realized that the assumption that emotional suppression has a health endangering effect was a hypothesis of historic validity. As is well known, a few years later it was Sigmund Freud (1904/1905, 1942, p. 240) who used similar words in an analysis of hysteria concerning suppressed emotions: »He that has eyes to see and ears to hear may convince himself that no mortal can keep a secret. If his lips are silent, he chatters with his fingertips; betrayal oozes out of him at every pore «.

Wilhelm Reich (1933) considered, what he called muscular armoring to be a physical manifestation of repression and suppression in the form of muscular activity used to prevent suppressed emotional stimuli from being transformed into action. Thus, he considered suppressive processes to be relevant to numerous, particularly psychosomatic diseases. In 1935, Helen Flanders Dunbar published many case studies in which she described emotional causes that, in her opinion, were specifically connected with physical diseases. Franz Alexander (1950) tried to describe in a more physiological way in his standard work of "Psychosomatic Medicine " the consequences of blocking emotions as the central cause of psychosomatic diseases. A huge field of research including many different methods and empirical articles (see the following monographs and anthologies: Traue \& Pennebaker 1993; Pennebaker 1995; Vingerhoets et al. 1997; Traue 1998) have arisen from the above-mentioned historical roots. Accordingly, in this 
field of research no one asks if the inhibition of feelings has a harmful effect on human organisms, but rather why and how structural, physiological, endocrine, immunological or subjective disease processes are connected with the processing of emotions and particularly their inhibition.

\section{Theoretical aspects of emotional behavior}

About twenty years ago it became apparent that research on emotions was lacking in the field of psychology. By this time Bruce W. Heller (1983, p. 190), criticizing the behavioral and cognitive dominance in the field, lamented ironically that Descartes did not say: »I feel therefore I am «, but preferred the thinking process and thus introduced a philosophy according to which emotions were less important than cognitions. He assumed also that it would be difficult to objectify emotions for empirical and experimental research; and that therefore, it would be better to avoid them. The horse of emotionality disappeared from the stable for centuries. It was ignored that emotions are strongly influenced by thoughts and vice versa, and that both processes are inseparably connected with each other.

Today, this is no longer the case. Current theories assert that emotions represent a complex structure composed of the following different elements:

1) Expressiveness of facial expressions, gestures and the whole body

2) Cognitive assessment of internal and external stimuli

3) Physiological and endocrine activation

4) A cognitive plan of action and an action tendency

5) Subjective experience and linguistic representation

Just as a river changes its course and flow over time, when discussing the phenomenology of emotions, the chronological process has to be considered. Emotions are a process. They separate the behavioral reaction from its stimulus by replacing fixed, reflex-like stimulus-response patterns or instinctive, innate trigger mechanisms with flexible behavioral responses. By doing so, fixed reflexive responses are replaced by cognitive appraisal processes of stimuli and situations. Especially the facial expression component of emotional behavior is a central part of interpreting which possible 
action tendencies and intentions of the individual will be communicated into his social environment. Only by doing so, does emotional behavior gain its regulating function not only within but also between individuals. Based on the described complexity of emotions and their process, functions and modes of function can be derived from emotions that enable us to classify the role of emotional inhibition (see Traue 1998 and 1999).

\section{Emotions give subjective meaning}

Emotions are a reaction to situations and give these situations personally relevant meaning. Here, situations are to be considered in a broad sense and comprise external (physical, social and informational) and internal (interoceptive and mental) stimulus patterns. For some stimulus patterns the emotional meanings are more standardized, i.e. more phylogenetically determined, than for others. However, some complex or ambiguous situations can only be assessed emotionally by a cognitive analysis. When intense stimulating events occur during traumatic experiences the possibility of cognitive assessment can be strongly reduced.

\section{Emotions aid communication}

Emotions help individuals adapt to their environment. The emotional structures and functions have developed in an evolutionary process, which spans not only the evolution of the nervous system, but also human social life. Although phylogenetically newer structures override older cerebral structures, they do not completely neutralize their function. Therefore, emotional behavior is based on vital, meaningful reactions that are experienced directly and contain a strong impulse to act. This urge to act can only be controlled to a certain extent. Since emotional processing has developed phylogenetically in step with human social life, the existence of a human being depends on the emotional expressiveness of its fellow human beings. 


\section{Emotional behavior is based on neurobiological structures}

The entire central and peripheral nervous system is involved in emotional processes, as mental functions are involved in emotional experience via perception, attention, activation, consciousness and language. However, the neurobiological structures that are host to these functions can contribute to very specific aspects of emotional experience. Part of the central nervous structure known as the limbic system is mostly important for the processing of discrete emotions. The limbic system integrates sensory input and information from the cortex into emotional units. Recent studies emphasize that sensory information can be processed more rapidly via thalamic circuits within the amygdala than within the cortex itself. This means that certain stimuli can lead to emotional reactions without being processed consciously. The fact that the quality of emotional reaction depends on neurobiological structures is also reflected in the predominance of negative emotions that are obviously more necessary for the survival of human beings than positive emotions such as curiosity, joy and love.

\section{Emotions can be both a process and a state}

Emotions are mainly produced when information is processed. Processing of outer stimuli patterns is structured hierarchically from sensation to cognition. Emotions can also arise from inner stimuli (e.g. fantasies, ideas or memories). Since inner stimuli always contain emotional information, emotions are directly produced. Thus emotions can always be reproduced by memory independently of when they first occurred in a person's life.

\section{Emotions are physical and mental}

Emotional processes correspond directly with central, motor and autonomic nervous activity, central regulations being more important than peripheral feedback. Theoretically this derives from the communicative 
function of emotional processes. Empirical evidence for this comes from the stability and inter-individual agreement about emotional expressive behavior and autonomic nervous correlates. Endocrine and immunological reaction patterns differentiate between positive and negative emotions but not within these two emotional classes.

\section{Emotional behavior is subject to self-regulation}

The control of emotional reactions by suppression or inhibition has a stronger effect on motor behavior, especially expressive emotional behavior, than on the other components of emotion, and modulates it qualitatively and quantitatively. Even socio-cognitive processes have substantial influence on this component of emotion. Secondary emotions such as shame and guilt depend on an individual's capacity to anticipate the consequences of his or her behavior or emotional reaction.

\section{The historical roots of the term: »Inhibition «}

Before we turn to the inhibition of emotions, a short outline of the term »inhibition «in modern scientific history should be given. Several years ago the scientific historian, Roger Smith, professor at the Institute for Scientific History at Lancaster University, discussed in his impressive book »Inhibition « (1992) the scientific origin of the term. Smith maintains that inhibition is a central issue permeating the arts, social science and scientific theories and that within a systemic conception of human self-regulation it is fundamental. At the end of the 19th century, there was a shift from biological models of body and soul to systemic theories of human regulation. Before that, the term inhibition was used in the sense of suppression as a crucial element to the establishment of hierarchical orders in social structures, as well as the power the soul has over the body. In C.S.Sherrington's (born in 1857) neurophysiology, I. P. Pavlov's (born in 1849) theory of the higher nervous system and S. Freud's (born in 1856) psychoanalysis the term inhibition played a central role. These three experts were not only contemporaries, they also had training in 
experimental research and started their research work at a time in which important discoveries were made in the field of neurophysiology.

The three scientists Sherrington, Pavlov and Freud developed the concept of inhibition in different scientific contexts. These contexts have in common that they postulate activating and inhibiting forces and that they describe regulating mechanisms of equilibrium or homeostasis. The idea of adapting the individual to different environmental conditions and the idea of communication between partial and whole systems is part of these contexts. A dominance of inhibiting influences on a neuronal, centralnervous or mental level is considered to be dysfunctional. The physiological theory of inhibition has been applied to general psychological and social concepts. These initially theoretical (and empirically based) assumptions have been popularized and transformed, so that people with dysfunctional regulation have been characterized as neurotic, psychotic and physically ill. Hence, even in colloquial »theories « the inhibited type of person is considered to be socially disturbed, unimaginative in his intellectual world, deviant in his behavior and prone to psychosomatic disorders.

\section{The inhibition of emotions}

In the Western cultural tradition, actions based on feelings are disparaged. Soon after birth, parents try to teach their children the culturally appropriate manner of dealing with feelings. Parental advisory books are full of suggestions of how to make infants give up their utterances of displeasure. These books more or less say that "the whining little ones " should show their feelings the way the adults think it to be appropriate. The fact that a baby cries when she or he is hungry is accepted. A baby's protest without being hungry is not so easily accepted, and can be very annoying, especially at night, when parents want to sleep. By three years of age, parents expect their children not to refuse to go to preschool, because they would rather stay with their parents. Later, children learn not to destroy other children's toys, not to scratch cars, not to use any physical violence in discussions. In short, they learn to regulate their feelings on their own.

As young human beings grow up, they will find their emotional needs and expressions in conflict with their social group and learn to control 
their emotions by means of anticipating positive and negative consequences of their expression. Some people succeed in this emotional self-control -i.e. in the harmonization of personal motives and their personal and cultural value system - and others do not or are less successful. Emotional selfcontrol that serves social life within a group can have negative consequences for an individual as the inhibition of feelings has its price. In this chapter, the way in which inhibited emotionality negatively affects individual health is discussed.

Since there is no golden standard of emotional self-control for human social life, a number of questions arise. 1) Where do the rules for emotional behavior in a given social community originate? 2) Who decides which emotional expression is appropriate and which is not? 3) What changes may have occurred in the course of history?

With a critical view on the social traditions of emotional expression, Stephan L. Chorover writes in his book »From Genesis to Genocide « that only certain human beings are always in a position to carry out manipulations of their own emotions, that these manipulations are always made in a social context and that these manipulations are often used to regulate the behavior of other human beings $(1979$, p. 16). In this sense emotional inhibition can be part of a general behavior strategy. There is very likely a considerable social inequality with regard to emotional inhibition.

\section{Civilization and commercialization of feelings}

Emotional control is always effected in a social context defined by historical, political and social conditions. Elias (1936) analyzed the social changes of dealing with emotions, covering the historical epoch between the Middle Ages and Modernity. One of the basic ideas of his inspiring theory discusses the wounds that can be caused by the shift of interpersonal emotional expressiveness to an implosion back into the individual self. Part of the tensions and passions that in former times directly burst into an interpersonal fight, nowadays have to be managed by and within the individual. While drives and passionate affect may no longer manifest in the external world, they are nonetheless quite often fighting, not less violently, within the individual. This semi-automatic internal struggle does not always have a happy 
ending. The self-transformation that life in our society requires does not always lead to a new equilibrium in the conflictual world of drives.

Norbert Elias (1936, p. 330 f.) formulates three central arguments concerning emotional self-control:

1) The more the accumulation of political and economic power increases, the more the expression of emotional behavior is restricted.

2) Politeness as a form of emotionally controlled behavior proliferated from nobility to the general public as a sign of social and political suppression. Table manners and living traditions changed concomitantly with the control of aggressiveness while thresholds for shame declined considerably. Roaring, hitting, screaming and natural signs of digestion such as farting, belching and spitting were progressively considered indecent. Due to the internalization of these new rules of behavior, control and suppression shifted from external to internal exertion.

3) The process of increasing affect control sharpened the separation of private and public worlds and may have reached its temporary pinnacle in present middle-class society. Bath and sleeping rooms have become private so that many emotions can only be experienced and lived within these very restricted areas. While, for example, in the Middle Ages, common bath and sleeping rooms were the rule, they are nowadays rather the exception.

Wouters (1986) asserts that diminished social barriers between persons and groups of persons require increased self-control within social life, and that children, although they rarely have an authoritarian upbringing which teaches them fixed limits, will later be expected to exert extremely high self-control.

The same amount of emotional control a society generally requires from its members will be required in stress reactions. Thus, the availability of psychotropic drugs and psychotherapeutic interventions such as meditation, relaxation, cognitive therapy and hypnosis, which can cushion or reduce emotional reactions, can all be interpreted as signs for the necessity of emotional inhibition. In Germany, for example, general practitioners prescribe about one package of psychotropic drugs per inhabitant per year.

In the fifties, the social scientist $\mathrm{C}$. Wright Mills realized that people were becoming more and more absorbed by the world of labor: »The part 
of their professional life in which they could act "freely « using their own personality is now organized as well and transformed to a living but at the same time obsequious instrument for distributing the freight « $(1956, \mathrm{p}$. 45). During 150 years of industrialization, labor was dominated by the production of goods more than today where the focus increasingly is on business and rendered services. However, the world of labor is now more than ever interested in subordinating or exploiting formerly private aspects of the personality of the working people, whose individual and private feelings get commercialized. This commercialization concerns the use of feelings for profit as well as the control of feelings.

Many settings for work and sometimes even for life are more or less hierarchically structured and function according to governmental control systems including rules which have been set up by authorities and which have to be followed by subordinates. Most institutions follow this scheme even if from time to time attempts are made to change them into so-called person-centered systems. Especially in times of economic crises, there is a tendency to break the rules, normally firmly established in bureaucracy. Increased control over emotions and communication among subordinate employees is supposed to also affect their creativity, thus causing losses to the institution. Even if the consequences of releasing dynamic working power are often drastic, e.g. when complete management structures are dissolved, the real power structure and hierarchies between enterprises and subordinate employees or superiors and subordinates remain untouched. These changes often veil the conflict of interests and the power structure. Such conditions do not help individuals to deal with their own and other persons' feelings.

The most important rules in governmental control systems and hierarchical structures are:

1) Feelings of proprietors and superiors are more important than those of subordinates. The feelings of these persons have to be thoroughly observed, analyzed and recognized, and have to be taken care of.

An average person's feelings are less important and must be controlled. Their open expression could be harmful and at the risk of one's safety.

These rules also apply to institutions which are proud of their liberalism. To tolerate the emotional behavior of higher ranking persons during professional debates requires lower ranking people to suppress their own 
feelings of frustration and anger. Without being able to come up with numbers, we are convinced that this emotional labor contributes considerably to the stress of our working life.

Another aspect of controlling one's feelings in the context of labor has to be mentioned. Arlie Hochschild examined the emotional labor in different private and professional spheres of life, especially those of stewardesses and tax collectors. Both professional groups are conspicuously characterized by a specific use of feelings and emotional labor in their work. In training syllabuses of these professions, trainees are systematically taught how to use their feelings. Hochschild sociologically defines emotional labor as a management of feelings, aiming at the formation of a publicly presentable body and facial expression and the suppression of undesirable facial expressions (Hochschild 1983).

Emotional labor "requires the showing and suppressing of feelings in order to preserve the outer attitude which has the desired effect on other persons " - this concerns the desired positive effects on flight passengers and the desired negative effects such as inducing fear in subjects regarding taxation. As a result of her study, Hochschild confirms that emotional labor is increasing in almost all professions of social, administrative and commercial services and that due to this fact, a new dimension of alienating human beings from the products and results of their own work is arising. Based on selfpresentations in detailed interviews Hochschild formed four groups with different strategies of emotional labor: (1) Members of the instrumentally oriented group claim to be actively acting persons who use feelings in their professions, but although they use their feeling instrumentally they do not believe that their personality would really change. (2) Members of the second group report themselves as adapted to their own emotionality. They express situation-specific feelings but keep their real feelings private. (3) A third group of persons observes a change of their emotional behavior under the influence of emotional labor. Hochschild coined the term emotionally deformed group for them. They gradually adapt to the professional demands. (4) The forth group finally adopts an active adaptation with respect to the professional demands of their job. According to the situation they try to change, to suppress their feelings or to »really « create necessary feelings.

The term of emotional labor especially applies to the third and forth group. Here, most personal deformations and the highest stress caused by 
the management of feelings arise. As emotional workers, human beings are not only alienated from the direct results of their own work but also from themselves, as nothing in one's inner emotional life is more directly connected to one's own personality than personal feelings. Emotional labor in commercial and social services and social care is potentially effective and professional since nobody wants to interact with grumpy people. But what is the price for this emotional labor when inner tensions grow to cope with the professional demands on emotional self-control?

Another indicator of an increasing commercialization of human emotionality, particularly in western neo-capitalistic countries, is that real feelings become a scarce interpersonal good. Never before have there been so many offers from psychological experts to help fellow human beings to get in contact with themselves and with their own authentic feelings. These offers refer to their professional as well as to their private life. They emanate from the experience that the manipulation of emotions exacts the high social price of an increasing distance between the individual and his emotional self. It is true that emotional labor is necessary for human social life, but emotions should not be at the mercy of commercialization. To the extent that this commercialization is spreading, the experience and sharing of authentic feelings will be forced back and fade out more and more from interpersonal everyday life.

\section{Individual differences in the inhibition of emotions}

Persons differ considerably in the extent of their expressive emotional behavior. This behavior fulfills different functions: Expressive behavior serves as an interpersonal signal system which is used to communicate emotional evaluations of situations to the social environment. It is considerably involved in regulating social behavior. Facial feedback to expressive behavior provides essential information for the evaluation of situations. If expressive behavior is inhibited, the regulation of social behavior is disturbed and the individual is deprived from an essential source of information for evaluating situations. Studies conducted from different perspectives show that inhibited emotional behavior has to be considered a risk factor for the origin and maintenance of psychosomatic disorders. 
It is a constituent factor of a model of health and illness which describes the bio-psychosocial interactions between emotional inhibition and disorders in health as pathways (see also Traue 1998). Here, the inhibition of emotional behavior is classified in different types which, depending on the intensity of the emotional disorder, influence the course of diseases.

\section{Typology of emotional inhibition}

The inhibition of emotional behavior is a complex action which cannot be reduced to a simple process since emotional behavior itself is very complex. According to Kagan et al. (1988) emotional inhibition is based on a genetic tendency but socialization considerably modulates the development of emotionality, especially with regard to expressive behavior. Finally cognition arising from dealing with stressful situations has to be integrated into a theory of the interrelation of inhibition and disease, as emotional action is dependent on cognitive processes, and the central-nervous representation of self-concepts and situations is mediated cognitively. The connections between inhibited emotionality and disease processes are presented by a model of health and illness which describes neurobiological, socio-behavioral and cognitive pathways between emotional inhibition and disease. Four types of emotional inhibition can be distinguished (Traue 1998, Traue \& Deighton 2000, Traue 2001): ${ }^{1}$

1) Genetic inhibition

2) Repressive inhibition

3) Suppressive inhibition and

4) Deceptive inhibition

GENETIC INHIBITION of emotional expressiveness describes avoidance behavior, social retreat and fear of strangers. The assumption of a genetically determined inhibition is based on the observation of children at different developmental stages who exhibit considerable individual differences in emotional expressive behavior which correlate with autonomic hyper-reactivity (Field

1 For more detailed information on the presentation of emotional implosion see Traue (1998) and Traue et al. (1997). 
et al. 1982). Confronted with unfamiliar situations and novel environmental stimuli little children show clear differences in behavior. About $15-20 \%$ of healthy children between the age of 1 and 2 years are afraid of new situations, avoid new stimuli, and are described as behaviorally inhibited. About $25-30 \%$ show the opposite pattern, and are described as uninhibited. The neurobiological basis of these behavioral tendencies is analyzed more thoroughly in the next section. According to Kagan a great proportion of inhibited behavior is inherited. However, the older these children grow, the smaller the genetic influence on emotional expressiveness becomes. Furthermore it has been shown that there is a higher heritability factor in the group of extremely inhibited children, so the more extreme the inhibition, the bigger the biological basis of behavior.

Inhibited persons are also described as shy. Experts talk about genetic inhibition when someone is longing for personal contact but is inhibited, and not when someone is tired, uninterested or lazy and is therefore not seeking contact. It is not a matter of active contact avoidance, as this would be attained by different behavior, but rather passive avoidance: Persons with genetic inhibition may find nonsocial situations attractive and will avoid personal contact due to their fear of punishment or anticipation of frustration.

Genetic inhibition can be observed in about $10-15 \%$ of all infants within the first two years of their life and is considered to be a characteristic which becomes more and more stable when they grow older. Inhibited children and young persons show special neurobiological characteristics. Inhibited behavior, which in its origin is genetically determined, interacts with conditioning and stress and can thus be intensified or reduced by conditions in the environment. If children are expressively inhibited in the first months of their life, they will have problems in the relationship to their caregivers. Thus, it is very likely that these children will experience a certain lack of social care and less positive responses to their behavior.

REPRESSIVE INHIBITION of emotional behavior occurs when a person cannot completely experience or tolerate emotional episodes with all their physiological, social and cognitive facets. The terminology of defense mechanisms comprises such terms as splitting-off, denial, dissociation and repression. With repressive inhibition, physiological and subjective 
components of emotional behavior will be repressed and cognitive aspects will be emphasized. Since physiological components are no longer integrated into behavior, the motivation for expressive-emotional behavior decreases as well. Unfortunate consequences of this repressive process are an extended activation of physiological, endocrine and immunological activation and a lack of coping. In stressful situations this leads to extended psycho-physiological reactions and ineffective coping (Schwarz \& Kline 1995).

SUPPRESSIVE INHIBITION means that a person experiences emotional episodes completely and consciously but for some reason intentionally suppresses these episodes completely or partially. This suppression can be either arbitrary or conditioned by socialization. Resulting from suppression, physiological activation can occur which is similar to repressive inhibition, social regulation can be disturbed by lack of expressiveness and cognitive processing can be incomplete. The suppression of emotional experience can refer to different aspects of emotional behavior. The attempt to suppress cognitive components of emotional experience leads to an increased attention towards these split-off elements of emotional behavior which paradoxically results in an increased cognitive focus on suppressed contents. The processing of negative emotions will be impaired by suppressive inhibition, even if a person is conscious of this suppression, as potential coping behavior is missing. Gross \& Levenson (1993) presented various silent film scenes to subjects (one neutral film scene with a park and two medical scenes with burnt skin and an amputation) and examined the effects of suppressive inhibition. From earlier attempts, the research team knew that both aversive film scenes were mainly judged to be disgusting and always provoked corresponding nonverbal behavior. Half the subjects were asked not to show their feelings. As could be expected, subjects who were given the »inhibition « instruction could control their facial expression. Somatic activity in the form of body movements and touching their face were significantly reduced. The deliberate suppression of emotional expression led to increased sympathetic arousal. Subjective disgust ratings were slightly reduced but ratings of anger, pain, grief, embarrassment and tension tended to increase. Contempt, a feeling that is expressively similar to disgust, was also significantly increased.

Deception, as a specimen of emotional inhibition, refers to when we are misinformed about another person's subjective emotional experience. 
DECEPTIVE INHIBITION describes a strategy in dealing with emotions and usually refers to the communication of emotional content or to nonverbal behavior. Deceptive inhibition is usually incomplete but still requires a considerable amount of psychological power which can be manifested in vegetative arousal during deceptive attempts. Other consequences of deception are the incomplete processing of negative events and restricted social support which can be even more problematic. Buck (1984) differentiates three types of deception: non-emotional, stressful and emotional deception. Since deception without any emotional background can be neither recognized by behavior nor cause any physiological reactions, it is not of interest here. Rather it is not deception in general but stressful and emotional deception, which is of crucial interest. If deception is accompanied by conflict its behavioral manifestations can be easily recognized. People blink more often, delay an expected response, clear their throat more often, talk slower and have more speech impediments when they talk.

The Guilty Knowledge Test (GKT) is a laboratory model for stressful inhibition by deception. By using this method, an increased heart rate, breathing frequency and blood pressure could be shown for the moments of deception - these are all physiological reactions which are also known as a stress response. Video recordings which were made during the act of deception showed that inhibition not only leads to a physiological increase in arousal but also to a general inhibition of facial activity. For the duration of vegetative arousal the face seemed to freeze.

\section{Pathways between stress, emotional inhibition and health disorders}

Inhibition of emotions leads to disease via neurobiological, socio-behavioral and cognitive pathways. And even if the inhibition of emotional behavior does not cause disease, it can maintain disease or delay healing. Physiological over-arousal can have the same negative effect as an over-stimulated endocrine system or a dysregulated immune system. Healing is enhanced by caring treatment from the social environment. Inhibited emotional processing itself does not necessarily have to cause diseases but it can influence the course of diseases. The present model differentiates between health 
disorders and disease behavior. A detailed (and graphic) presentation of the pathway model can be found in Traue (1998). The following sections provide detailed descriptions of the three pathways from inhibition to disease.

\section{Neurobiological pathways}

There is no doubt that behavioral inhibition in little children in the presence of novel social stimuli, which is expressed in emotional inhibition, anxiety and shyness, has a neurobiological basis. Particularities of this behavioral pattern can be shown in low thresholds for new stimuli and in hyperactivity of certain physiological systems which is expressed as an increased fright reaction, increased muscle tension and for uninhibited children in overactive and easily excitable neurotransmitter systems.

A concept which is frequently discussed in this context assumes that the balance between activation and inhibition of neural activity favors inhibition.

Jeffrey Gray $(1972,1976)$ and Henri Laborit $(1986,1993)$ postulate a system of behavioral inhibition in the central nervous system. According to Gray, the behavioral inhibition system (BIS) reacts to unknown stimuli, pain stimuli and the frustrating absence of an expected response-contingent reward. Neuro-anatomically, the BIS is located in the septum-hippocampusfrontal (SHF) cortical region. Pharmacological substances such as barbiturates, alcohol and tranquilizers have a disinhibitory effect on the SHF region. Lesions in the SHF region also have a disinhibitory effect. The basic scheme of Gray's studies follows an experimental approach and avoidance conflict tested with animals. The experimental animals learn a certain behavior to get rewarded. When the reaction is learned, a punishing stimulus will be set that activates the BIS and reduces this learned behavior. This finally leads to a behavioral stop by passive avoidance with a simultaneous increase of neuro-physiological arousal and attention. The behavioral inhibition system reacts to conditioned punishing stimuli, stimuli which signal the end of a reward and to unknown stimuli. If then a fear-reducing substance is given which blocks the BIS, the effect of these stimuli will disappear and can be followed by approach behavior. 
Based on his own studies and other scientific studies of unavoidable aversive stimuli, Henri Laborit $(1986,1993)$ developed a brain model of behavioral inhibition which is similar to Gray's and essentially refers to structures that enable the conditioning of fear stimuli. He considers behavioral inhibition itself to be a learned behavior. According to Laborit, the inhibition is transmitted via the ventral-median hypothalamus by releasing norepinephrine and ACTH. This is influenced by the dorsal septum region, the dorsal hippocampus and the lateral amygdala. The neurotransmitter serotonin $(5-\mathrm{HT})$ increases the arousal of behavioral inhibition. Hereby, the dopaminergic system and acetylcholine influence the prefrontal cortex. According to Laborit, the serotonergic projections from the raphe nuclei into the neuronal system of septum, hippocampus and the prefrontal cortex as well as the cholinergic projections to the frontal cortex and the ascending pathways from the formatio reticularis and the basal nucleus of the amygdala are part of the behavioral inhibition system. The ascending cholinergic pathways to the cortex activate ACTH and the emission of cortisol. Henri Laborit describes the involvement of conditioned behavioral inhibition in the origin and maintenance of diseases as follows: » (1) Glucocorticoids lead to a blockage of the immune system. It can be deduced that if microbial infection or abnormal cells appear, which normally would be controlled by immune defenses, then an infectious or neoplastic episode may develop unhindered. This explains the relation between infections and neoplasms in behavioral situations where gratifying action is inhibited. It also shows that infectious agents or cancer-causing factors are not the only ones involved. (2) The peripheral release of norepinephrine at sympathetic system terminals will cause a generalized vasoconstriction, thus a decrease in the vascular container. Also, glucocorticoids lead to a retention of salts and water and so there is an increase in the vascular contents. The combination of these two facts leads to hypertension. Experimental observations also suggest that numerous somatic disturbances are generated by the same process: atherosclerosis, gastric ulcers, renal lesions, etc. (3) Concerning mental pathology, it is not in the scope of the present work to develop the consequences of inhibition of action. They may be summarized by saying that, in our opinion, anxiety and its neurotic consequences result from the conflict between the impulse to act and the inhibition of action, in this case from learning that punishment will follow the 
release of the impulse. Psychosis could be a flight into the imaginary when inhibition is too painful to be tolerated. (4) It is also interesting to note that in the scheme we have outlined, free radicals $\left(\mathrm{H}_{2} \mathrm{O}_{2}\right.$, leukotrines, endoperoxides) are capable of destroying cellular membranes, those of lysosomes in particular, which may cause neural death. This could be a primary and fundamental step towards understanding the chronic state of certain diseases (Parkinson, Alzheimer), just as in acute lesions caused by cerebral anoxia. « (p. 73-74, 1993).

A clinical study can be cited to explain the relevance of Gray's and Laborit's postulated connections between behavioral inhibition and physiological and endocrine activations for the origin of a disease: In a study by Cole et al. (1996) with $222 \mathrm{HIV}$-seronegative, homosexual men as subjects, the negative effects of suppressing emotionally important sexual preferences could be demonstrated. By means of a secrecy scale the subjects were separated in four groups according to the degree of their outing: completely out of the closet, mostly out of the closet, half in and half out of the closet und mostly or completely in the closet. This also defines the degree to which homosexuals hide their sexual tendencies outside of their intimate area of life. The regression analysis resulted in a dramatic increase of disease frequency combined with an increased observance of secrecy for almost all infectious diseases as well as for skin cancer. Considering all diseases, the probability of disease doubles with each secrecy level. This effect has to be taken even more seriously since the effects of age, ethnicity, education, social status, health behavior (e.g. drug abuse, sleeping habits and physical fitness) and psychological influences such as depression, fear and negative affectivity - even repressive coping style - were eliminated from the data. Using a cross-sectional design such as this, this quasi-experimental study can not provide proof that inhibition leads to illness, and other causal directions are also possible (e.g. becoming sick could lead to less outing). However, all things considered, this study provides strong evidence that the degree of hiding sexual tendencies can be a releasing factor for disease.

Aside from the postulate of central nervous activity which can hinder emotional behavior, the hypothesis of conscious and unconscious processing of emotional information has been pursued since the beginning of the split-brain research. Former studies by Sperry $(1966,1974)$ describe the following: The right hemisphere processes graphic information (e.g. a naked 
woman in an experiment) into an appropriate emotional reaction (blushing, giggling), without knowing linguistically which information finally led to this emotional reaction. If we did not know that the transfer of information from the right to the left hemisphere was interrupted due to their separated corpus callosum, we would probably think of the defense mechanism of repression. It is well known that the female subject of this experiment does not intentionally suppress emotional content. Due to her neuropsychological deficit she is rather not able to describe it. Even if the results of split-brain human beings cannot be easily transferred to healthy people, these observations favor various ideas of a differentiated involvement of both hemispheres in the dysfunctional processing of emotional stimuli which is shown in inhibited expressiveness or alexithymia, since even with healthy human beings there are differences between the left and the right hemisphere in processing emotional information. This is of great importance for the issue of inhibited emotional expressiveness: With manual reaction the right hemisphere is faster than the left one in recognizing faces as carrying emotional information. But when reactions have to be linguistic, the right hemispheric advantage will disappear. Facial recognition tasks for physiognomic invariance (i.e. recognizing faces from different perspectives) are better solved by the right hemisphere. With the processing of acoustic stimuli the right hemisphere is dominant in identifying the emotional tone of language. From the difference in emotional processing within the left and right hemisphere, a neuropsychological mechanism can be derived which explains dissociations between emotional experience, emotional expressive behavior and physiological reactions that are typical for different phenomena of inhibited emotionality and personality (see Traue, 1988, 1998; Lane et al. 1995, 1996). An unpublished MRI study by Gündel et al. (unpublished) confirms the hypothesis that the volume of the right hemisphere correlates with the characteristic of alexithymia - but specifically only the anterior gyrus cinguli and only in male subjects.

\section{Socio-behavioral pathways}

Inhibited emotional processing means that people who cannot (appropriately) show their feelings in interpersonal situations have an essential deficit 
in communication, emotional exchange and relationships. As soon as a child is born, innate emotionality has an effect on the communicative behavior of parents. The more expressive a baby, the more parents address it using emotional facial expression. Emotional expressive reactions have an intensifying effect on both sides. The longing for emotional exchange always stays alive (Rimé 1995).

Children with lower expressiveness and increased sympathetic arousal are easier to condition since they react more strongly to punishing stimuli. Under unfavorable socialization conditions within the family, school or religious groups, growing emotional expressiveness can be suppressed and sympathetic arousal can be increased. There are other effects: Expressive children (and adults) are popular, seem to be more attractive and are superior in attaining their ends. Salovey and Mayer (1990) coined the term of »emotional intelligence « to describe this capability. When expressive persons use emotional intelligence, they succeed in building a social support system which, under stressful conditions, might serve as a buffer against stress and may reduce health-damaging effects.

Under extreme trauma emotional intelligence comes into play only if the person stays in his or her social environment and if they use their still existing emotional resources little by little to rebuild their social relationships (Traue et al. 1997; Traue 1998). Learning processes under extreme trauma can condition hyperactive arousal patterns in the autonomic nervous system - ranging from fear to external numbness and internal apathy. After having been conditioned, these human beings suffer from strong oscillations between high emotional arousal and emotional insensitivity, between the urge to run away and numbness.

\section{Cognitive pathways}

Memories of emotional experiences are often unpleasant, especially when they refer to problematic episodes in life. Therefore many human beings try to suppress thoughts of such events. Since such thoughts are crucial parts to emotional reactions, attempts to suppress them are inhibitions of emotional behavior. The energy used to suppress such thoughts is not available for use in other cognitive processes, resulting in reduced cognitive functioning. 
The ambivalence with respect to emotional expressiveness can be interpreted as cognitive inhibition. King et al. (1992) formulated a theory of emotional ambivalence according to which the need for emotional expressiveness can cause conflicts which result in ambivalence with respect to one's own expressiveness. King's ambivalence questionnaire was translated into German and the connection between physical and psychological health and emotional ambivalence was tested on a sample of healthy test subjects. (Deighton \& Traue, in preparation).

A factor analysis of the German AEQ resulted in two different ambivalence aspects regarding content. One factor summarized questions which referred to the consequences of emotional expressiveness, e.g. if someone fears that his expression of anger will be taken badly by another person. That is why we called this factor effect ambivalence. The second factor comprised questions which referred to one's ability to show an emotional expression, e.g. if someone wants to show his feelings but does not succeed. Therefore we call this factor competence ambivalence. Effect ambivalence mostly refers to negative emotions, whereas competence ambivalence is more connected with positive feelings. Both factors also differ in terms of health data. While effect ambivalence correlates with physical pain and depressive symptoms, high values in competence ambivalence correlate with a lack of social support.

Another cognitive pathway of suppression is caused by a cognitive style of processing emotional events lacking emotion . Many aspects have to be encoded linguistically in order to process an emotional event completely. Inner dialogues as well as the communication of emotional experiences require such linguistic transformations. Some decades ago scholars of psychosomatic medicine coined the term alexythymia for emotionless language to describe the incapability of dealing mentally or linguistically with emotional events. Maintaining a complete cognitive representation of emotional events is important in order to delete such events from the network of fear within the brain and to reconnect them to less frightening experiences. Due to the fact that in mental fear, networks of isolated emotional contents are associated with corresponding sympathetic arousal, physiological arousal could be interpreted as a physical symptom of disease.

Cognitive transformations of stressful events do not necessarily require the suppression of emotional information. One may capitalize on 
Shakespeare's insight in Hamlet: »there is nothing either good or bad, but thinking makes it so. " and can try to change a certain way of feeling by changing one's way of thinking. Although reappraisal may include thought suppression, it mainly comprises reframing an emotional event in unemotional terms and the separation of internal states from external stimulation. In a recent study with functional magnetic resonance imaging, Ochsner et al. (2002) showed that the effective reduction of subjective negative affect by cognitive reappraisal correlates with increased activity in the left lateral, medial prefrontal and cingulate regions and decreased activation in the amygdala and medio-orbitofrontal cortex. Although these findings suggest that cognitive processes are involved in emotional regulation and can change subjective aversive experience, questions remain about the functional significance of this brain activity and their relevance for clinical populations. However, these observations are consistent with findings from treatment studies in depressive and obsessive-compulsive disorders, which found a normalization of prefrontal and amygdala activity. Therefore cingulate, prefrontal and amygdala activation seems to be relevant for emotional regulation.

\section{Emotions in psychotherapy}

Internal experience and expression of emotions are often the focus of attention in psychotherapy. Here, emotional behavior cannot be considered apart from cognitive processes and actions, since these functions can cause emotions and are also influenced by emotions. In the field of psychotherapy, which deals with the whole human being, emotional behavior can only be examined in connection with other basic psychological functions.

From a historical point of view, psychoanalysis used an energy term to describe emotional behavior since cybernetic concepts and ideas of processing information had not been developed at that time. In this context, Freud originally regarded emotional behavior in the sense of psychological energy, which had its origin in drives and instincts, the id. In the field of psychoanalysis the attention to emotional processes derived from clinical experiences with treating conditions formerly called hysteria. According to Freud, affects that are not abreacted stay mentally connected with the corresponding situation. Even if they remain unconscious, they can still cause 
neurotic behavior in which aspects of originally experienced or resulting motives are symbolized. Freud also took the view that an abreaction of experienced affect could either occur spontaneously during or following an affect-provoking situation or could result from a therapeutic intervention. Here, he had different possibilities in mind, which ranged from directly acting out one single event up to finely tuned talking about the trauma in several sessions (Freud, 1895).

Even if in traditional psychoanalysis the support of expressive emotionality had been forced back in favor of purely cognitive processes, these ideas were not lost. Michael Balint reported that Sandor Ferenczi experimented with so-called "active techniques «. Ferenczi assumed that in therapeutic sessions suppressed emotions, conflicts or thoughts can be stirred up in a way that they become almost conscious but due to their negative content are finally transformed into physical symptoms which can be understood and interpreted as neurotic symptoms.

Patients' physical behavior in therapy should be observed in regard to its expressive quality as the conflict between an emotional impulse to act and its suppression is reflected in physical-expressive behavior. Nowadays we talk about a different kind of nonverbal expressive behavior. Ferenczi regarded the liberation of the original impulse to act as an important step in therapy. In this context he suggested extending the passive analytical attitude by either recommending to patients that they actively live out their impulses or by advising them not to do so. From the present point of view it is amazing to see the amount of mental and intellectual effort analysts of the twenties took to find out whether they should advise patients to masturbate or not whenever they had that sexual impulse. However, outside the field of psychoanalysis it has been common practice to actively help patients to cope with their inhibited emotions, needs and impulses to act.

According to Ferenczi, his active technique considerably differed from the traditional method of free association. Ferenczi argued with his colleagues whether it was possible to hold a neutral position towards patients. He maintained that professional dishonesty might have the same damaging effect on patients as their original trauma (for Ferenczi's methods of treatment see Balint, 1967).

Two psychoanalysts must be mentioned when therapeutic concepts for the change of emotional inhibition are discussed: Carl G. Jung and 
Wilhelm Reich. Both were psychoanalytic traditionalists but represented such radical views that new therapeutic schools derived from their work. Years before the already mentioned current discussion of emotion theory, Jung pointed out some essential differences between cognitive and emotional appraisals of environmental stimuli. According to him, cognitions lead to true-false-judgments whereas emotions lead to good-bad evaluations. Jung believed that both appraisal processes were rational, whereas in his opinion processes of perception and intuition were irrational and had to undergo rational evaluation by cognitions and emotions. All of these four psychological functions are important to behavior. In therapy underdeveloped psychological functions need to be supported. Another aspect of Jung's perspective regards the psyche as a self-regulating system. Suppressed memories and experiences become emotionally connected mental complexes within the unconscious and must be controlled by the individual. Rigid attitudes and behavioral rules adopted by the individual counteract these denied or suppressed mental complexes. In therapy the individual needs to experience these dreaded libidinal or destructive emotions in order to learn how to tolerate and accept them. It needs to be mentioned that Jung did not regard libido in a narrow sexual sense but as mental energy.

More radical and determined than any other psychoanalyst, Wilhelm Reich turned his back on a "purely intellectual understanding " of human emotions and on traditional psychoanalysis which in his opinion had made a mistake in giving up catharsis. He was interested in searching therapeutic possibilities for releasing suppressed emotions in therapy.

Wilhelm Reich assumed that any resistance to experience, to live and express feelings would be firmly embodied within the personality. Based on the psychological analysis of »character armoring ", as he called this resistance, he developed psycho- and physio-therapeutic interventions to break these armors. Basically he assumed that fear and fear of aggressiveness would cause the suppression of emotional impulses. Wilhelm Reich concentrated on physical symptoms and expressions in therapy more consistently than Ferenczi. He began to be more interested in nonverbal behavior than in verbal statements of his patients. He did not regard physical symptoms as transformed psychological energy but as manifestations of suppressed emotion. 
According to Reich, muscular tensions did not result from the repression of feelings, but were the somatic mechanisms of the suppression of feelings themselves. His therapy aimed at breaking muscular armor, revealing suppressed emotional impulses and developing an awareness of situations in which the suppression of emotions had originated.

Wilhelm Reich did not value the concept of catharsis for its own sake. This was often misunderstood. He believed that catharsis helped to release emotions and make patients aware of them. Emotions should not be released and expelled from internal psychic processes, but should rather be consciously perceived and accepted. Cathartic elements in therapy were followed by a phase of mental processing of experienced feelings. Suppression was counteracted by realization and clarification of the involved psychological mechanisms. Wilhelm Reich worked with a mixture of breathing techniques, massage and physical exercises which increased the general level of arousal to a point at which finally the resistance to suppressed feelings could be given up. In Reich's therapy this support of emotional expressiveness was the ideal way to physical and mental health.

Emotional behavior plays an important role in body-oriented forms of psychotherapy. Strongly influenced by Reich's ideas of emotional inhibition and his therapeutic techniques, Alexander Lowen developed Bioenergetic Analysis - a therapeutic school that considers physical and intensive emotional experience to be the central elements of healing. In line with Wilhelm Reich, Alexander Lowen assumes that emotional inhibition absorbs psychic energy which would be necessary for an individual's active coping with his environment. Similar to C.G. Jung, he emphasizes the function of emotional stimuli for the interpretation of internal and external stimuli: Knowledge associated with feelings becomes understanding and can induce change (Lowen, 1975, S. 62).

According to Alexander Lowen, expressive emotionality leads to an improved coordination of psychic and somatic processes and integrates thoughts and attitudes. Bioenergetic theory considers emotional expressiveness to be healthy because of its regulating effects on the social environment as well as on the personal self. Physical movements and changes in posture support the expression of strong emotions.

Lowen considers both neurotic and psychosomatic disorders to be caused by traumatic experiences or emotional deprivation in childhood. 
It is possible to react both with inhibition of emotions and impulsivity. Lowen was convinced that parents instill the suppression of feelings into their children because they have low tolerance for their and other children's emotional expression. LikeWilhelm Reich, Lowen considered the abreaction of and liberation from trauma, mainly experienced in childhood, to be the crux of therapy.

In response to the results of research in childhood development and emotion theory, finally even in the field of psychoanalysis it has become generally accepted that emotional behavior has to be understood as a communication system by means of which needs, wishes and situational appraisals can be more directly communicated into the social environment nonverbally than verbally.

Current psychotherapeutic theories almost unanimously hold the experience and expression of emotions as very important for understanding patients and their disorders. Emotional behavior in therapy is often regarded as the key to change: Greenberg and Safran describe this change in the following episode:

»I saw a therapist for a few months and began to talk about some of my feelings of isolation and frustration. The issues became somewhat more crystallized for me, but, somehow or other, things didn't really change for me on an emotional level. Then I began to see a second therapist. Somehow or other, this therapist began to get me in touch with what I was feeling inside. I remember, much to my surprise, breaking down and crying in the second session. I began by making weak sounds and soon was wailing and crying at the top of my lungs. Gradually, over the next five minutes, the intensity of my crying subsided. I began to talk about the pain and desperation I was experiencing inside in a way I never had before. Perhaps I had never felt it that way before, either. I continued talking about my sense of longing for human contact, and the way I felt caged in by my anxieties and fears of rejection, my guilt feelings about having a sexual relationship. In the following weeks I began to feel more and more motivated to do things to change my life. It was a few months before I made big changes on the outside, but I'll always date the beginning of the change back to that episode» (Greenberg \& Safran 1987, S. 4).

Patients start to react emotionally at a certain point in the therapeutic process. This emotional moment differs from former feelings in its intensity and its 
expressive component. Patients really feel themselves and thus obtain insight. Due to this intense feeling they are able to talk more clearly about their needs and to develop motives. The crucial emotional processes are subjective experiences of feelings, physical involvement, emotional expression as well as resultant motivational and cognitive changes. Many psychotherapists would agree on the fact that psychological problems often result from the blocking or avoidance of potentially adaptive emotional behavior and that psychotherapeutic interventions aim at overcoming the resistance to emotions and at revealing emotional experience, and that furthermore the complete living out of a specific emotional episode leads to a change of emotional experience and thus enables new adaptive reactions in problematic situations.

If we would like to analyze how the science of psychotherapy deals with patients' emotional processes, one cannot really talk about " psychotherapy « since in numerous psychotherapeutic traditions the theory which they are based on differs considerably from their therapeutic interventions. In theory differences between schools are bigger than in therapeutic practice.

\section{Four dimensions of emotion therapy}

Greenberg \& Safran (1987) postulated four essential dimensions. These are based on different psychotherapeutic perspectives from which emotional behavior is viewed within the corresponding therapeutic concepts and techniques of treatment:

1) Emotional discharge

2) Emotional insight

3) Facilitating adaptive emotions

4) Exposure and habituation

Different psychotherapeutic perspectives evaluate these four dimensions in different ways. But if one aspect (or more) is used within a psychotherapeutic intervention, it will be crucial to aim at a complete living out of an emotional episode including subjective experience, emotional expressiveness, physiological arousal and interactive functions.

Emotional Discharge: Many psychotherapeutic methods contain elements of catharsis more or less explicitly. Mostly cathartic elements are 
considered, e.g., to help to activate repressed memories or to offer patients a safe room where they do not have to flee from suppressed or avoided emotional reactions. Only a few therapists believe in the salutary effects of directly living out emotions such as the adherents of primal therapy. Even Thomas (1983), being an advocate of cathartic therapy, believes that catharsis is particularly effective if patients can observe their expression of previously repressed or suppressed emotions from a certain distance and if they can step by step remove their emotional inhibition by means of this self-experience and self-observation. The release of suppressed emotionality should be embedded in therapeutic strategies which strive for changes in a patient's self-concept after having had a cathartic experience, so that lasting changes can derive from cathartic experience. If assumptions concerning stress and coping were prominent in therapy, one aim of emotional discharge would be to direct the psychological effort necessary for suppressing emotions towards coping with stress. This aim can only be achieved if patients previously acknowledged the possibility and power of emotional discharge.

EMOTIONAL INSIGHT: Although in psychotherapies which are largely cognitively oriented catharsis of emotional arousal is considered to be ineffective or at best to have ephemeral effects, the significance of emotional experiencing is not questioned. On the contrary: Purely intellectual understanding of one's own behavior - even of disturbed behavior - is to be distinguished from insight. Insight in therapy only occurs when emotional aspects of experience are processed concommitantly with remembered events. Insight is only effective if patients understand their emotional impulses in the overall context of their personal and cultural value system and integrate the episode into a personal narrative. In psychoanalysis, for example, the rendering process serves the goal of emotionally enriching previously superficial, psychological experiences via the mechanism of transference. The closer current emotional experience and intellectual processing are related to each other, the more likely patients are to change. In client-centered therapy therapists specifically focus on emotional nuances in their patients' verbal communications. Client-centered therapy deals not so much with suppressed emotional impulses but rather with emotionally communicated aspects patients' self-concepts and relationships to social objects of their interpersonal environment. Here, emotions 
are regarded as meaningful processes by means of which an individual evaluates its inner and outer world. In this respect, insight is always connected with emotional involvement. Among other forms of therapy, client-centered therapy explicitly focuses on the opposite process, on the constructivist perspective of experienced emotionality. Any personal self-concept is always the result of a mental construction and can only be complete if it includes emotional experience. In this respect, subjective and present emotional experience are necessary to change self-concepts in therapy.

FACILITATING ADAPTIVE EMOTIONS: By facilitating adaptive emotions, the self-centered individual perspective is extended. For an individual within his social context, emotions control his behavior and experience within interpersonal contact. Sympathy, attraction and the rejection of other persons are regulated by emotional experience. In this context the role of emotions as a system of processing information according to an intra- and inter-individual dimension is emphasized. It opens the view beyond the individual. Therapeutic methods which restrict their striving to a reduction of unwanted feelings, neglect and ignore the adaptive value of emotional reactions.

The communicative meaning of expressive emotional behavior is at the core of humanistic therapy. Expressive emotional behavior is supported, thereby enabling patients to translate their subjective spectrum of feelings into interpersonal communication. The same applies to social competence training in behavior therapy where expressive emotional behavior is practiced or supported in order to fulfill needs or solve problems.

Present development of different therapeutic concepts is characterized by an effort to integrate new findings from psychobiology. This applies to cognitive-behavioral therapies which help traumatized patients to cope with the neurobiological effects of extreme stress on emotional behavior as well as to the field of psychoanalysis which nowadays integrates findings from developmental psychology into its own concepts. Expressive emotional behavior probably developed phylogenetically from general behavior patterns (e.g. vomiting rejected food) to the communication of appraisals (e.g. disgust). Hence, the adaptive function of expressive behavior for living in groups must be high.

EXPOSURE AND HABITUATION: Methods of catharsis, flooding or implosion are based on different theoretical ideas. They also have their roots in 
different therapeutic approaches (early psychoanalysis and behavioral therapy). Their theoretical background assumes that potentially existing emotional behavior might disturb patients if it is triggered by certain stimuli or if it is unwanted. Early psychoanalysts viewed these unwanted reactions as well as their qualitative transformations via abreaction in catharsis, so-to-say as creating a valve for discharging psychic energy. Behavior therapists thought that extinction and counter-conditioning would be an appropriate means of therapy, either by conditioning an alternative reaction to situations which previously caused unwanted feelings or by revoking consequences which increased unwanted feelings. Emotional behavior has to occur during therapeutic sessions, i.e. it has to be introduced by an active process, to make therapeutic strategies successful. This is an essential common feature. In recent behavioral-therapeutic discussions, the term of emotional processing is used. Emotional processing reflects the transition of therapeutic goals from reducing unwanted emotions to behavioral alternatives. Stanley Rachman says: "As a start, emotional processing is regarded as a process whereby emotional disturbances are absorbed, and diminish to the extent that other experiences and behaviour can proceed without disruption. " (Rachman 1980, 51). All of these therapeutic methods use different techniques from different psychotherapeutic schools but have in common that they seek to promote emotional processing or the understanding of one's emotions.

\section{Conclusion}

The described model of health and illness postulating a connection between inhibited emotionality and disorders of health is a non-deterministic pathway model which describes neurobiological, socio-behavioral and cognitive pathways between stress and emotional activation, their processing by inhibition and clinical consequences. In particular for headaches and back-pain, diseases of the cardiovascular system and cancer, there are numerous empirical and partly even experimental results which prove beyond theoretical assumptions the clinical relevance of inhibited emotionality as a risk factor to health. Contemporary psychotherapists and scholars of psychosomatic medicine are not alone having discovered the damaging effects of emotional inhibition 
to physical health. In various civilizations, the individual costs for the inhibition of individual emotions which are based on social constraints - and good reasons - were and are at least partly reduced by rituals of emotional openness. Rituals of emotional openness in ethnic groups and former historical epochs are nowadays removed from their mostly religious context by modern psychotherapy and experience a secularized form of professionalism as well as a wide proliferation of psychological concepts into everyday life.

Psychological therapy processes which are well-known in the field of psychosomatic and behavioral medicine aim almost unanimously at changing emotional behavior in order to reduce physical stress reactions. In conclusion it must be said that in the field of psychotherapy, emotionregulating interventions have proven to be very successful with the treatment of emotional problems and inhibition and with disorders of physical health (Traue, 1998).

\section{References}

Alexander, F. (1950): Psychosomatic Medicine. New York (Norton).

Balint, M. (1967): Sandor Ferenczi's Technical Experiments. In Benjamin B. Wolman (Ed.) Psychoanalytic Techniques, New York (Basic Books).

Buck, R. (1984): The communication of Emotion. New York (Guilford Press).

Chorover, S. L. (1979): From genesis to Genocide. The Meaning of Human Nature and the Power of Behavioral Control. NewYork (Bantam Books)

Cole, S. W., M. E. Kemmeny, S. E. Taylor \& B. R. Visscher (1996): Elevated physical health risk among gay men who conceal their homosexual identity. Health Psychology 15(4), 243-251.

Damasio, A.R. (1994): Descartes' Error. Emotion, Reason and the Human Brain. New York (G. P. Putnam's Son).

Deighton, R.M. \& Traue, H.C, (in preparation): Emotionale Ambivalenz: Zusammenhänge zu Körpersymptomen, Depressivität, und sozialer Interaktion. Drei Studien mit dem AEQ-G18

Elias, N. (1936): Über den Prozeß der Zivilisation. Frankfurt a.M. (Suhrkamp).

Erk, S. \& Walter, H. (2000): Denken mit Gefühl. Nervenheilkunde 19, 3-13.

Field, T.M., Woodson, R., Greenberg, R, \& Cohen, D. (1982): Discrimination and imitation of facial expressions in neonates. Science, 218, 179-181. 
Dunbar, H.F. (1935): Emotions and bodily changes: A survey of the literature: 1919-1933. New York (Columbia University Press).

Freud, S. (1904/1905, 1942): Bruchstücke einer Hysterie-Analyse. Gesammelte Werke, London (Imago, Band V, S. 240).

Freud, S. (1895): Entwurf einer Psychologie. In: Aus den Anfängen der Psychoanalyse. Frankfurt (Fischer Verlag (1975)).

Gray, J. A. (1972). The psychophysiological nature of introversion - extraversion: A modification of Eysenck's theory. In: Nebylitsyn, V.D. \& Gray, J.A. (Hrsg.) Biological basis of individual behavior. New York: Academic Press.

Gray, J.A. (1976): The behavioral inhibition system: A possible substrate for anxiety. In: M. P. Feldmann \& A. M. Broodhurst (Hrsg.). Theoretical and experimental base of behavior modification. New York (John Wiley \& Sons).

Greenberg, L. S. \& J. D. Safran (1987): Emotion in Psychotherapy. New York (The Guilford Press).

Gross, J. J. \& R. W. Levenson (1993): Emotional suppression: Physiology, selfreport and expressive behavior. Journal of Personality and Social Psychology 64, 970-986.

Gündel, A., A.O. Ceballos-Baumann, A. López, J. Deus, N. Cardoner, B. MartenMittag, M. von Rad und J.Pujol (unpublished): Alexithymia correlates with the size of the right anterior cingulate gyrus.

Hochschild, A.R. (1983): The Managed Heart. Commercialisation of Human Feelings. Berkley/Los Angeles (The University of Calofornia Press).

Heller, B. W. (1983): Emotion: T-oward a biopsychosocial paradigm. In: L. Temoshok, C. van Dyke \& L. S. Zegans (eds.) Emotions in Health and Illness. New York (Grune \& Stratton, 190-194).

James, William (1890): The principles of psychology. New York (Holt).

Kagan, J., J. S. Reznick \& N. Snidman (1988): Biological bases of childhood shyness. Science 240(4849), 167-71.

King, L. A., R. A. Emmons \& S. Woodley (1992): The structure of inhibition. Journal of Research in Personality 26, 85-102.

Laborit, H. (1986): L'inhibition d'action. Paris (Masson (2. Ed.)).

Laborit, H. (1993): Inhibition of action: interdisciplinary approach to its mechanism and physiopathology. In: H. C. Traue \& J. W. Pennebaker (Hrsg.): Emotion, Inhibition, and Health. Seattle (Hogrefe \& Huber Publishers, 57-80).

Lane , R. D., L. S. Kiveley, M. A. du Bois, P. Shamasundara \& G. E. Schwartz (1995): Levels of emotional awareness and the degree of right hemispheric 
dominance in the perception of facial emotion. Neuropsychologia, 33, 525-538.

Lane, R. D., L. Sechrest, R. Reidel, V. Weldon, A. Kasznlak \& G. E. Schwartz (1996): Impaired verbal and nonverbal emotion recognition in alexithymia. Psychosomatic Medicine, 58, 203-210.

Lowen, A. (1975): Pleasure: A creative approach. Baltimore (Penguin Books). Mills, C. W. (1956): White Collar. New York (Holt).

Ochsner, K.N., Bunge, S.A., Gross, J.J. and Gabrieli, J.D.E. (2002): Rethinking Feelings: An fMRI Study of the Cognitive Regulation of Emotion. Journal of Cognitive Neuroscience 14:8, pp. 1215-1229

Pennebaker, J. W. (1995): Emotion, disclosure, \& health: An overview. In J. W. Pennebaker (ed.): Emotion, disclosure, and health. Washington, D. C. (American Psychological Association, 3-10).

Rachman, S. (1980): Emotional Processing. Behavior Research and Therapy 18, 51-60. Reich, W. (1933, Edition 1973): Die Charakteranalyse, Frankfurt a.M. (Fischer Verlag).

Rimé, B. (1995): Mental Rumination, Social Sharing, and the Recovery from Emotional Exposure. In: J. W. Pennebaker (ed.): Emotion, disclosure, and health. Washington, D. C. (American Psychological Association, 271-292).

Salovey, P. \& J. D. Mayer (1990): Emotional Intelligence. Imagination, Cognition, and Personality 9, 185-211.

Schwartz, G. E., \& Kline, J. P. (1995): Repression, Emotional Disclosure and Health. In J. W. Pennebaker (Ed.): Emotion, disclosure, and health. Washington, D.C. (American Psychological Association)

Sherrington, C. S. (1932): Inhibition as a coordinative factor. In: Nobel Foundation (Hg.): Nobel Lectures (Physiology and Medicine 1922-1941), 278-289.

Smith, R. (1992): Inhibition: History and meaning in the sciences of mind and brain. Berkeley, Los Angeles (University of California Press).

Sperry, R. W. (1966): Brain bisection and consciousness. In: J. Eccles (Hrsg.): Brain and conscious experience. New York (Springer).

Sperry, R. W. (1974): Lateral specialization in the surgicaby seperated hemispheres. In: F.O. Schmitt \& F.G. Warden (Hrsg.): The Neurosciences Third Study Program. Cambridge, Mass. (MIT Press).

Traue, H.C. (1988): Cerebrale Lateralität, emotionale Prozesse und Krankheit. In W. Ehlers, H.C. Traue und D. Czogalik (Hrsg.): Bio-psycho-soziale Grundlagen für die Medizin. Heidelberg (Springer). 
Traue, H. C. (1998): Emotion und Gesundheit. Die psychobiologische Regulation durch Hemmungen. Heidelberg (Spektrum).

Traue, H.C. (1999): Emotion. In: U. Tewes \& K. Wildgrube (Hg.): PsychologieLexikon. München (Oldenbourg, 93-97).

Traue, H. C. \& R. M. Deighton (2000): Emotional Inhibition. In: G. Fink (ed.): Encyclopedia of Stress. San Diego (Academic Press, Vol. 2, 32-38).

Traue, H. C. (2001): Emotional Inhibition and Health. In N. J. Smelser \& P. B. Baltes (Eds.): The international encyclopedia of the social and behavioral sciences (Vol. 7, pp. 4449-54). Oxford, England (Elsevier).

Traue, H. C., M. Kessler \& V. Lee (1997): Pathways linking emotional inhibition, psychosomatic disorders and pain. In: Ad Vingerhoets, F.v. Bussel \& J. Boelhouwer (eds.): The (Non) Expression of Emotion in Health and Disease. Tilburg (Tilburg University Press, 193-210).

Traue, H. C. \& J. W. Pennebaker (eds.) (1993): Emotion, Inhibition and Health. Toronto (Hogrefe \& Huber Publishers).

Vingerhoets, Ad, F.v. Bussel \& J. Boelhouwer (eds.) (1997): The (Non) Expression of Emotion in Health and Disease. Tilburg (Tilburg University Press).

Wouters, C. (1986): Formalization and informalization, changing tension balances in civilizing process. Theory, Culture and Society 3, 1-19.

A key note with this topic was given by Harald C. Traue at the annual conference of the IIBA 2003 in Salvador de Bahia in Brazil. It is based on a shortened, partly amended and translated version of Traue, H.C. and Deighton, R.M. (2003) Emotionale Hemmung als Risikofaktor für die Gesundheit. In: A. Stephan and H. Walter (Hrsg.) Natur und Theorie der Emotionen. Paderborn: Mentis Verlag.

Prof.Dr. Harald Traue, Health Psychology, Dept. of Psychosomatic Medicine and Psychotherapy, University of Ulm, Am Hochsträss 8, FRG, e-mail: harald.traue@medizin.uni-ulm.de 